\title{
Correction to: Gastroparesis Following Immune Checkpoint Inhibitor Therapy: A Case Series
}

\author{
Jessica Atieh $^{1} \cdot$ Jordan Sack $^{2,3} \cdot$ Richard Thomas $^{3,4} \cdot$ Osama E. Rahma $^{3,5} \cdot$ Michael Camilleri $^{1}$ (D) $\cdot$ Shilpa Grover $^{2,3}$
}

Published online: 7 August 2020

(c) Springer Science+Business Media, LLC, part of Springer Nature 2020

\section{Correction to: Digestive Diseases and Sciences https://doi.org/10.1007/s10620-020-06440-x}

The original version of the article unfortunately contained an error in the Table 2. In the column 'Motility immunerelated adverse event' of Table 2, the term 'Intestinal pseudo-obstruction' was inadvertently removed in the final version. Corrected Table 2 is given below.

The original article has been corrected.

The original article can be found online at https://doi.org/10.1007/ s10620-020-06440-x

Michael Camilleri

camilleri.michael@mayo.edu

1 Clinical Enteric Neuroscience Translational and Epidemiological Research (CENTER) and Division of Gastroenterology and Hepatology, Mayo Clinic, 200 First St. S.W., Rochester, MN, USA

2 Division of Gastroenterology, Hepatology, and Endoscopy, Brigham and Women's Hospital, Boston, MA, USA

3 Harvard Medical School, Boston, MA, USA

4 Department of Radiology, Brigham and Women's Hospital, Boston, MA, USA

5 Department of Medical Oncology, Dana-Farber Cancer Institute, Brookline, MA, USA 
Table 2 Prior case reports of patients with gastrointestinal Motility immune-related adverse event

\begin{tabular}{lllllll}
\hline $\begin{array}{l}\text { Motility immune- } \\
\text { related adverse } \\
\text { event }\end{array}$ & Gender & ICI & Target & Tumor & References \\
\hline $\begin{array}{l}\text { Intestinal pseudo- } \\
\text { obstruction }\end{array}$ & 57 & Male & Pembrolizumab & PD-1 & Neuroendocrine \\
& 62 & Male & Nivolumab & PD-1 & NSCLC & [17] \\
& 71 & Female & Pembrolizumab & PD-1 & GEJ carcinoma & [35] \\
Constipation & 62 & Male & Ipilimumab & CTLA-4 & Melanoma & [25] \\
Ileus & 66 & Male & Ipilimumab + nivolumab & CTLA-4 +PD-1 & Merkel cell carcinoma & [19] \\
\hline
\end{tabular}

$P D-1$ programmed death-1, NSCLC non-small cell lung cancer, GEJ gastroesophageal junction

Publisher's Note Springer Nature remains neutral with regard to jurisdictional claims in published maps and institutional affiliations. 